\title{
ASSOCIATION BETWEEN KNOWLEDGE AND COMPLIANCE OF TAKING IRON/FOLIC ACID SUPPLEMENTS DURING PREGNANCY
}

\section{CHRISTIANA R TITALEY ${ }^{1 *}$, ENRIKA RAHAYU ${ }^{1}$, RITA DAMAYANTI ${ }^{1,2}$, DINI DACHLIA ${ }^{1}$, RATU AYU DEWI SARTIKA ${ }^{1,3}$, AMRY ISMAIL ${ }^{1}$, ADHI SANJAYA ${ }^{4}$, ELVINA KARYADI ${ }^{4}$}

${ }^{1}$ Center for Health Research, Faculty of Public Health, Universitas Indonesia, Depok, Indonesia. ${ }^{2}$ Department of Health Education and Behaviour Science, Faculty of Public Health Universitas Indonesia, Depok, Indonesia. ${ }^{3}$ Department of Public Health Nutrition, Faculty of Public Health, Universitas Indonesia, Depok, Indonesia. ${ }^{4}$ Micronutrient Initative, Indonesia. Email: christiana_rialine@yahoo.com

Received: 21 April 2017, Revised and Accepted: 13 July 2017

\section{ABSTRACT}

Objective: In Indonesia, pregnant women are recommended to take a minimum of 90 tablets of iron/folic acid (IFA), to prevent iron deficiency anemia. Our analysis aimed at examining the extent to which improved knowledge on IFA supplementation is associated with women's compliance with taking a minimum of 90 IFA tablets during their last pregnancy in four districts in Indonesia.

Methods: Data were derived from a cross-sectional study conducted in four districts, that is, Lebak and Pandeglang District (Banten Province) as well as Purwakarta and Subang District of West Java Province, Indonesia on June 2014. We used information from 436 mothers who delivered their baby in the last 6 months from the time of the survey and received at least 90 IFA tablets during her last pregnancy. Logistic regression analysis was used to examine the role of knowledge after controlling for confounders and other significant predictor on compliance with taking a minimum of 90 IFA tablets during pregnancy.

Result: Significant association was found between knowledge of IFA supplements and compliance. Compared to women with poor knowledge of IFA supplementation, the odds of taking a minimum of 90 IFA tables increased by almost $100 \%$ in women with moderate knowledge (adjusted odd ratio $[\mathrm{aOR}]=1.96,95 \%$ confidence interval [CI]: 1.17-3.30, $\mathrm{p}=0.011$ ); and by more than four times (aOR=5.42, 95\% CI: 1.76-16.68, $\mathrm{p}=0.003$ ) in women with good knowledge of IFA supplementation. Other factors associated with compliance was attendance in at least four antenatal services (aOR=5.71,95\% CI: $1.28-25.53, \mathrm{p}=0.023)$ and pregnant women experience of no side effects resulting from taking IFA tablets during pregnancy $(\mathrm{aOR}=2.70,95 \% \mathrm{CI}$ : $1.63-4.46, \mathrm{p}<0.001)$

Conclusions: Efforts to increase women's knowledge on IFA supplementation through community-based education will increase women's compliance of taking IFA supplements. Strengthening counseling services on potential side effects of IFA supplementation and ways to manage them will also help to improve compliance.

Keywords: Iron/folic acid supplementation, Knowledge, Compliance, Indonesia.

(C) 2017 The Authors. Published by Innovare Academic Sciences Pvt Ltd. This is an open accessarticle under the CC BY license (http://creativecommons. org/licenses/by/4. 0/) DOI: http://dx.doi.org/10.22159/ajpcr.2017.v10s5.23126

\section{INTRODUCTION}

Iron deficiency anemia is one of the most common form of undernutrition in both developed and developing countries [1,2]. Children, pregnant, and post-partum women are adversely impacted by iron deficiency anemia [2]. Around $42 \%$ of pregnant women experienced anemia and around $50 \%$ are due to iron deficiency [3]. The effect of iron deficiency anemia on women and infant have been reported, including increased risk of maternal and neonatal mortality [4-6]. One of the interventions globally conducted to prevent iron deficiency anemia among pregnant women is by providing iron/folic acid (IFA) supplements during pregnancy.

Although pregnant women in Indonesia are recommended to take at least 90 IFA tablets, the 2012 Indonesia Demographic and Health Survey showed that nationally, only $32.7 \%$ women taking IFA tablets or syrup for 90 days or more during pregnancy [7]. Similarly, the 2012 Basic Health Survey reported that only 33.3\% pregnant women in Indonesia took IFA tablets for at least 90 days [8].

A cross-sectional survey was conducted in June 2014 by Center for Health Research Universitas Indonesia funded by Micronutrient Initiative aimed at examining the coverage and compliance of IFA supplementation among pregnant women in Lebak and Pandeglang District (Banten Province) and Purwakarta and Subang District (West
Java Province). This analysis aimed at examining the extent to which improved knowledge on IFA supplementation among those women is associated with their compliance with taking a minimum of 90 IFA tablets during pregnancy in those districts.

\section{METHODS}

Data source and study sites

Data were derived from a cross-sectional study conducted from June 06, 2014 to June 22, 2014, in Lebak and Pandeglang District (Banten Province) as well as Purwakarta and Subang District of West Java Province, Indonesia (Fig. 1).

\section{Study design}

The survey used a multistage cluster design. At the first stage, 64 clusters (village) were selected using the probability proportionate to size method. From each cluster, one hamlet was randomly selected using simple random sampling method. Household listing was carried out to identify all households and potential respondents living in the selected hamlet. Of the listed potential respondents, 10 women recently delivered in the last 6 months before the survey were randomly selected using systematic random sampling. Household interviews were then carried out to interview selected respondents at their house. Interviews were conducted by local trained interviewers. 


\section{Respondents and samples of the study}

Respondents of this study were mothers who delivered their baby in the last 6 months from the time of the survey and received at least 90 IFA tablets during her last pregnancy.

This analysis used information collected from 436 mothers, consisted of 67 (15.5\%) mothers in Pandeglang; 74 (16.9\%) mothers in Lebak; 169 (38.7\%) mothers in Purwakarta; and 126 (29\%) mothers in Subang.

\section{Outcome variable}

The outcome variable is women's compliance with taking a minimum of 90 IFA during her last pregnancy. This variable was constructed based on two questions addressed to mothers who reported that they received any IFA tablets (government and/or private tables) during their last pregnancy. The questions were: (1) "How many government IFA tablets (show the picture of government IFA tablets) did you take when you were pregnant?" (2) "How many private IFA tablets (show the picture of some examples of private IFA tablets) did you take when you were pregnant?" If women mentioned that they took both government and private tablets, the total number of IFA tablets was added.

\section{Main study factor}

The main study factor in this analysis is improved knowledge of IFA supplementation is associated with women's compliance with taking a minimum of 90 IFA tablets during their last pregnancy in four districts in Indonesia. This composite variable was constructed based on three questions: (1) "Have you ever heard of iron tablet? (scored '1' if women answered 'yes' and ' 0 ' if women answered "no")"; (2) "How many iron tablets should a pregnant woman take during pregnancy? (scored ' 1 ' if women answered ' $90+$ tablets' and ' 0 ' if women answered ' $<90$ tablets' or 'do not know')"; and (3) "What are the benefits of taking iron tablets during pregnancy? (score ' 1 ' was assigned to all correct answers provided, including 'to prevent anemia and its signs,' 'to prevent maternal death,' 'to prevent excessive bleeding at childbirth,' 'to prevent preterm infants,' and 'to prevent low birth weight infants')." The scores from these questions were added and divided into three groups (thirtiles) to represent three categories of knowledge, that is, poor, moderate, and high level of knowledge.

\section{Other covariates}

There were four groups of covariates examined: (1) Sociodemographic characteristics; (2) health-care services received during pregnancy; (3) knowledge about anemia; and (4) previous experience with IFA supplementation (Table 1). Variable of knowledge about anemia were constructed based on three variables: (1) Ever heard of anemia (score " 1 " for yes and " 0 " for no) and (2) knowledge about sign of anemia (score "1" for all correct answers, such as weakness,pale, tired, drowsiness; and score "0" for all incorrect answers); and (3) knowledge about prevention of anemia (score "1" for all correct answers, such as take IFA tablets or consume iron-rich food; and score "0" for all incorrect answers). The scores were added and divided into three categories of knowledge, that is, poor, moderate, and high level of knowledge. In the group of previous experience with IFA supplementation, two variables were included which were: (1) Age of pregnancy when mother took IFA tablet for the first time and (2) any previous experience of any side effects after taking IFA tablets.

Household wealth index was constructed using the principal components analysis method [9] using 13 variables: Main material of roof, wall, floor, main source of drinking water, ownership of toilet, type of toilet, type of final fecal disposal, and possession of radio, television, telephone or mobile phone, fridge, bicycle, and motorcycle. Using this composite variable, all households were then ranked then divided into quintiles, that is, poorest, poor, middle, rich, and richest.

\section{Data analysis}

Frequency distribution of all variables included in this study was examined using contingency tablets. This was followed by logistic

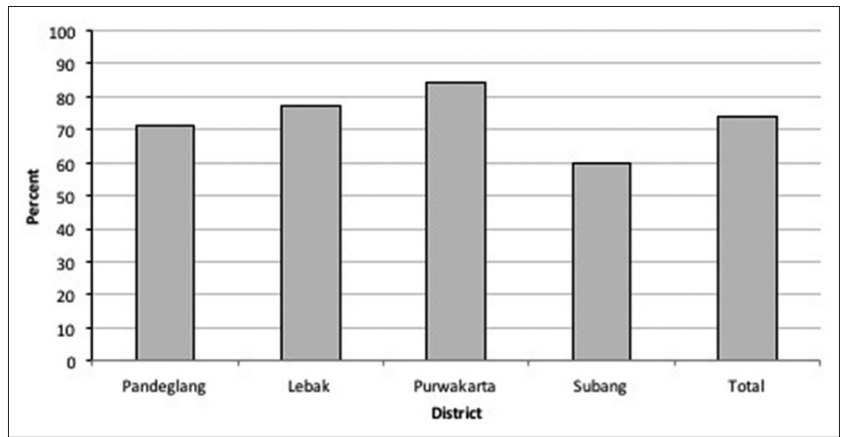

Fig. 1: Consumption of a minimum 90 iron/folic acid tablets during pregnancy by district

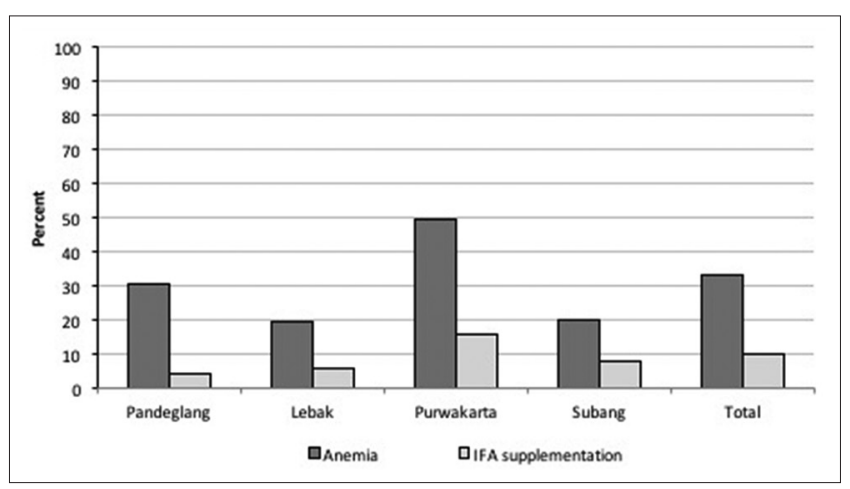

Fig. 2: Knowledge about anemia and iron/folic acid supplementation

regression analyses aimed at assessing the association between study outcome variable and the main study factor. In the first stage of logistic regression analysis, bivariate regression analyses were carried out to examine the relationship between the study outcome and the main study factor as well as other potential predictors, independently. In the second stage, multivariate analyses were performed to assess the association between study outcome and the main study factor after adjusting for both confounders and factors significantly associated with the outcome. The estimated measures of association were assessed using odds ratio (ORs). In the multivariate analyses, we employed backward elimination method to remove factors not significantly related to the study outcome using the significance level of 0.05 as well as non-confounders. Variable representing the district was retained in the final model regardless of its level of significance. In the final model, adjusted OR (aOR) and 95\% confidence intervals (95\% CIs) were reported for all variables in the model. All estimates were weighted by sampling probabilities taking into account the complex sample design. Stata/MP software (version 14.1; StataCorp) was used for all analyses.

\section{Ethics and research clearance}

Ethical clearance for this research was acquired from the Ethics Committee, Faculty of Public Health, Universitas Indonesia. Administrative clearance was obtained from the Ministry of Internal Affairs Republic of Indonesia and National Unity and Community Protection Office (Kesbanglinmas) at provincial and district level. Informed consent from respondents was obtained before the interview.

\section{RESULTS}

Our analysis found that of 436 mothers who delivered their baby in the last 6 months from the time of the survey and received at least 90 IFA tablets during her last pregnancy, 73.9\% (323 mothers) took at least 90 IFA tablets during pregnancy $(71.1 \%$ in Pandeglang; $77.1 \%$ in Lebak; 84.5\% in Purwakarta; and 59.6\% in Subang). 
The distribution of respondents by sociodemographic characteristics, health services received during antenatal care services, knowledge about anemia, and IFA supplementation as well as experience with IFA supplementation is presented in Table 1. Fig. 2 shows that overall, only $10 \%$ of women had high level of knowledge about IFA supplementation; ranging from only $4.3 \%$ in Pandeglang to $15.9 \%$ in Purwakarta.

After adjusting for all significant predictors, our analyses found a significant association between knowledge of IFA supplementation and women's compliance of taking a minimum of 90 IFA tablets during their last pregnancy. The odds of taking a minimum of 90 IFA tablets among women with moderate level of knowledge were doubled $(\mathrm{aOR}=1.96$, 95\% CI: $1.17-3.30, \mathrm{p}=0.011)$ the odds of women with poor level of knowledge. The odds in women with a high level of knowledge were more than 5 times (aOR=5.42, 95\% CI: 1.76-16.68, p=0.003) the odds of women with poor level of knowledge. Other factors associated with women's compliance with taking a minimum of 90 IFA tablets were women's attendance in at least four antenatal services (aOR=5.71, 95\% CI: 1.28-25.53, $\mathrm{p}=0.023$ ) and experience of no side effects from taking IFA tablets during pregnancy $(\mathrm{aOR}=2.70,95 \% \mathrm{CI}: 1.63-4.46, \mathrm{p}<0.001)$.

Table 1: Frequency distribution of respondents by different characteristics and consumption of a minimum 90 IFA tablets during pregnancy

\begin{tabular}{|c|c|c|}
\hline \multirow[t]{2}{*}{ Variables } & \multicolumn{2}{|l|}{ n (\%) } \\
\hline & Weighted & Consumption of a minimum 90 IFA tablets \\
\hline \multicolumn{3}{|l|}{ Sociodemographic characteristics } \\
\hline \multicolumn{3}{|l|}{ District } \\
\hline Pandeglang & $67.43(15.46)$ & $47.94(71.1)$ \\
\hline Lebak & $73.51(16.86)$ & $56.64(77.06)$ \\
\hline Purwakarta & $168.8(38.72)$ & $142.6(84.45)$ \\
\hline Subang & $126.2(28.95)$ & $75.22(59.59)$ \\
\hline \multicolumn{3}{|l|}{ Age of mother } \\
\hline$\leq 20$ years & $62.13(14.25)$ & $40.71(65.52)$ \\
\hline $21-25$ years & $94.11(21.58)$ & $64.97(69.04)$ \\
\hline $26-30$ years & $137.6(31.56)$ & $101.7(73.92)$ \\
\hline $31-35$ years & $92.53(21.22)$ & $74.68(80.71)$ \\
\hline $36+$ years & $49.65(11.39)$ & $40.33(81.22)$ \\
\hline \multicolumn{3}{|l|}{ Education of mother } \\
\hline No school/incomplete & $14.98(3.43)$ & $11.62(77.6)$ \\
\hline Completed primary school & $143.6(32.93)$ & $109.6(76.37)$ \\
\hline Completed senior high school & $118.9(27.27)$ & $89(74.86)$ \\
\hline Academy/university & $31.83(7.3)$ & $24.71(77.62)$ \\
\hline \multicolumn{3}{|l|}{ Occupation of mother } \\
\hline Homemaker & $380.7(87.32)$ & $280.1(73.58)$ \\
\hline Working/student & $55.29(12.68)$ & $42.24(76.41)$ \\
\hline \multicolumn{3}{|l|}{ Hosehold wealth index } \\
\hline Q1 richest & $144.7(33.2)$ & $104.3(72.08)$ \\
\hline Q2 & $91.09(20.89)$ & $69.91(76.75)$ \\
\hline Q3 & $69.19(15.87)$ & $54.3(78.47)$ \\
\hline Q4 & $74.54(17.1)$ & $52.14(69.94)$ \\
\hline Q5 poorest & $56.44(12.95)$ & $41.71(73.89)$ \\
\hline \multicolumn{3}{|l|}{ Services received during pregnancy } \\
\hline \multicolumn{3}{|l|}{ Number of ANC visit } \\
\hline$<4$ ANC & $8.11(1.86)$ & $3.071(37.88)$ \\
\hline $4+\mathrm{ANC}$ & $427.9(98.14)$ & $319.3(74.62)$ \\
\hline \multicolumn{3}{|c|}{ Type of services received during ANC } \\
\hline \multicolumn{3}{|c|}{ Knowledge of anemia } \\
\hline Poor & $207.4(47.57)$ & $147.3(71.01)$ \\
\hline Moderate & $83.77(19.21)$ & $57.02(68.06)$ \\
\hline Good & $144.8(33.22)$ & $118.1(81.54)$ \\
\hline \multicolumn{3}{|c|}{ Knowledge about IFA supplementation } \\
\hline Poor & $238(54.58)$ & $152.9(64.23)$ \\
\hline Moderate & $154(35.32)$ & $128.2(83.21)$ \\
\hline Good & $44(10.09)$ & $41.36(94)$ \\
\hline \multicolumn{3}{|c|}{ Experience with IFA supplementation } \\
\hline \multicolumn{3}{|c|}{ Time first taking IFA tablets in the last pregnancy } \\
\hline $1^{\text {st }}$ month & $92.04(21.11)$ & $62.66(68.08)$ \\
\hline $2^{\text {nd }}$ month & $121.8(27.94)$ & $101.7(83.45)$ \\
\hline $3^{\text {rd }}$ month & $75.64(17.35)$ & $55.3(73.12)$ \\
\hline $4^{\text {th }}$ month & $95.29(21.86)$ & $68.76(72.16)$ \\
\hline 5 month or more & $50.17(11.51)$ & $33.41(66.6)$ \\
\hline \multicolumn{3}{|l|}{ Experience of any side effects } \\
\hline Yes, any side effects & $109.7(25.15)$ & $71.77(65.44)$ \\
\hline No, no side effects & $325.3(74.61)$ & $250(76.86)$ \\
\hline Not taking IFA tablets & $1.053(0.24)$ & $0.59(56.17)$ \\
\hline
\end{tabular}

IFA: Iron/folic acid 
The results of univariate and multivariate analysis of factors associated with consumption of a minimum 90 IFA tablets during pregnancy are described in Table 2.

\section{DISCUSSION}

\section{Main findings}

Our study found that improved knowledge of IFA supplementation was significantly associated with women's compliance of taking a minimum of 90 IFA tablets during pregnancy. The likelihood of taking at least 90 IFA tablets during pregnancy increased along with the increased knowledge of IFA supplementation about whether women had ever heard of IFA tablets, the number of IFA tablets pregnant women should take during pregnancy and the benefits of taking IFA tablets for pregnant women and their children. Other factors significantly associated with compliance with taking a minimum of 90 IFA tablets during pregnancy were attendance in at least four antenatal care visits and women's experience of no side effects after taking IFA tablets. The results of this study provide insights about factors associated with women's compliance of taking IFA tablets during pregnancy. These factors should be therefore addressed, particularly by health workers to increase use of IFA supplements during pregnancy.

Knowledge of IFA supplementation and compliance with taking IFA supplements

Our study found that improved knowledge of IFA supplementation is associated with women's compliance with taking a minimum of 90 IFA

Table 2: Univariate and multivariate analysis of factors associated with consumption of a minimum 90 IFA tablets during pregnancy

\begin{tabular}{|c|c|c|c|c|c|c|}
\hline \multirow[t]{2}{*}{ Variable } & \multicolumn{3}{|c|}{ Univariate } & \multicolumn{3}{|c|}{ Multivariate } \\
\hline & OR & $95 \% \mathrm{CI}$ & $\mathbf{p}$ & aOR & $95 \% \mathrm{CI}$ & $\mathbf{p}$ \\
\hline \multicolumn{7}{|l|}{ Sociodemographic characteristics } \\
\hline \multicolumn{7}{|l|}{ District } \\
\hline Pandeglang & 1 & & & & & \\
\hline Lebak & 1.23 & $0.69-2.18$ & 0.480 & 1.53 & $0.82-2.85$ & 0.178 \\
\hline Purwakarta & 2.07 & $1.13-3.79$ & 0.019 & 1.75 & $0.90-3.40$ & 0.100 \\
\hline Subang & 0.64 & $0.35-1.14$ & 0.129 & 0.55 & $0.29-1.03$ & 0.063 \\
\hline \multicolumn{7}{|l|}{ Age of mother } \\
\hline \multicolumn{7}{|l|}{$\leq 20$ years } \\
\hline $21-25$ years & 1.15 & $0.63-2.11$ & 0.650 & & & \\
\hline $26-30$ years & 1.32 & $0.72-2.41$ & 0.376 & & & \\
\hline $31-35$ years & 1.89 & $0.92-3.9$ & 0.085 & & & \\
\hline $36+$ years & 0.9 & $0.95-4.89$ & 0.067 & & & \\
\hline \multicolumn{7}{|l|}{ Education of mother } \\
\hline \multicolumn{7}{|l|}{ No school/incomplete } \\
\hline Completed Primary School & 1.59 & $0.57-4.44$ & 0.372 & & & \\
\hline Completed Junior High School & 1.09 & $0.39-3.05$ & 0.873 & & & \\
\hline Completed Senior High School & 1.38 & $0.47-4.10$ & 0.557 & & & \\
\hline Academy/University & 1.84 & $0.43-7.96$ & 0.411 & & & \\
\hline \multicolumn{7}{|l|}{ Occupation of mother } \\
\hline Homemaker & 1.06 & $0.5-2.24$ & 0.872 & & & \\
\hline Working/student & 2.92 & $2.34-3.63$ & 0 & & & \\
\hline \multicolumn{7}{|l|}{ Household wealth index } \\
\hline \multicolumn{7}{|l|}{ Q1 richest } \\
\hline Q2 & 1.04 & $0.54-2.02$ & 0.904 & & & \\
\hline Q3 & 1.52 & 0.75-3.09 & 0.241 & & & \\
\hline Q4 & 0.86 & $0.46-1.60$ & 0.633 & & & \\
\hline \multirow{2}{*}{\multicolumn{7}{|c|}{ Services received during pregnancy }} \\
\hline & & & & & & \\
\hline \multicolumn{7}{|l|}{ Number of ANC visit } \\
\hline$<4$ ANC & & & & & & \\
\hline $4+\mathrm{ANC}$ & 0.5 & $1.51-24.90$ & -0.98 & 5.71 & $1.28-25.53$ & 0.023 \\
\hline \multicolumn{7}{|c|}{ Type of services received during ANC } \\
\hline Less variety & 0.75 & $0.43-1.30$ & 0.301 & & & \\
\hline Good variety & 1.67 & $1.03-3.52$ & 0.038 & & & \\
\hline \multicolumn{7}{|c|}{ Knowledge about anemia and IFA supplementation } \\
\hline \multicolumn{7}{|l|}{ Knowledge of anemia } \\
\hline \multicolumn{7}{|l|}{ Poor } \\
\hline Moderate & 0.86 & $0.5-1.49$ & 0.593 & & & \\
\hline Good & 1.51 & $0.91-2.48$ & 0.108 & & & \\
\hline Knowledge about IFA supplemen & & & & & & \\
\hline Poor & & & & & & \\
\hline Moderate & 2.02 & $1.25-3.26$ & 0.004 & 1.96 & $1.17-3.30$ & 0.011 \\
\hline Good & 4.84 & $1.68-13.95$ & 0.004 & 5.42 & $1.76-16.68$ & 0.003 \\
\hline Experience with IFA supplementat & & & & & & \\
\hline Time first taking IFA tablets in th & & & & & & \\
\hline $1^{\text {st }}$ month & & & & & & \\
\hline $2^{\text {nd }}$ month & 1.01 & 0.53-1.93 & 0.978 & & & \\
\hline $3^{\text {rd }}$ month & 0.63 & $0.32-1.24$ & 0.182 & & & \\
\hline $4^{\text {th }}$ month & 0.56 & $0.28-1.12$ & 0.100 & & & \\
\hline 5 month or more & 0.53 & $0.25-1.12$ & 0.097 & & & \\
\hline Experience of any side effects & & & & & & \\
\hline Yes, any side effects & & & & & & \\
\hline No, no side effects & 2.28 & $1.44-3.57$ & 0.000 & 2.70 & $1.63-4.46$ & $<0.001$ \\
\hline
\end{tabular}


tablets during pregnancy. This result confirmed findings from other studies showing the role of education, knowledge, and awareness with compliance [10-12].

Increasing women's knowledge and awareness could be conducted through effective counseling about IFA supplementation by health workers, for example, during antenatal care contact $[13,14]$. Studies showed that inadequate counseling was shown to be a barrier for women to consume IFA tablets [15]. Providing women with clear instructions about the intake of IFA tablet and educate them on the benefits of the tablets will improve compliance [16,17]. Taking into account the important role of health workers in improving compliance, efforts to improve health workers counseling skills is vital. Training or refresher training could target health workers, particularly midwives and cadres who are regularly in a close contact with pregnant women. Such trainings will help to increase their knowledge and skills in conducting health education and counseling to mothers [18].

Furthermore, provision of information, education, and counseling materials was also reported as an effective tool in improving positive health practices [19]. A study conducted in Indonesia reported that providing booklet regarding anemia improves knowledge and compliance with taking IFA tablets during pregnancy [20].

\section{Other factors associated with compliance}

This study shows that women who attended at least four antenatal care services were more likely to take a minimum of 90 IFA tablets during pregnancy, as shown other studies [21,12]. This indicates that effort to urge pregnant women to attend antenatal care regularly is important. Health workers and cadres should be encouraged to actively invite women to attend antenatal care through every contact opportunity. Moreover, side effects experienced by mothers due to taking IFA tablets were found as a barrier for compliance. This finding was supported by other studies $[16,22]$. This highlights the importance of increasing women awareness and knowledge including side effects that might occur after taking IFA tablets and how to overcome them.

\section{Strengths and limitations}

This analysis used a large sample size that provides adequate power to examine the role of improved knowledge about IFA supplementation and other potential predicators and compliance with taking IFA supplements during pregnancy. The use of mothers who delivered within the last 6 months before the time of survey will reduce recall bias.

Nevertheless, there are several potential predictors for compliance not available in the dataset, for example, the supply of IFA tablets as well as availability and quality of nutrition counseling and education by health workers. Similar to other cross-sectional surveys, this analysis also has the limitation of showing a cause and effect relationship. However, these limitations are unlikely will reduce the validity of the results of the analyses.

\section{CONCLUSION}

Our study confirmed the significant association between level of knowledge about IFA supplementation and women's compliance of taking a minimum of 90 IFA tablets during pregnancy. The compliance increased along with the increase levels of knowledge. This finding shows the need to increase mothers' awareness about IFA supplementation. Strengthening the counseling services to educate mothers about the benefits until the side effects and how to deal with the side effects of IFA supplementation is essential. Efforts to increase health workers' skills in delivering appropriate counseling are also important. The use of IEC materials such as leaflets or posters, could be conducted to provide information to mothers and their family members about IFA supplementation to increase mothers' compliance of taking a minimum of 90 IFA tablets during pregnancy.

\section{ACKNOWLEDGMENT}

We would like to thank micronutrient initiative in Indonesia for their continuous supports and guidance in this research. We also would like to thank Mr. Manoj Kumar Raut from the micronutrient initiative for his technical assistance in this study. We are grateful to staff from District Health Office in Lebak, Pandeglang, Purwakarta, and Subang. We are indebted to all respondents who participated in this study. This research was funded by micronutrient initiative.

\section{REFERENCES}

1. Stoltzfus RJ, Dreyfuss ML. Guidelines for the Use of Iron Supplements to Prevent and Treat Iron Deficiency Anaemia. Washington, DC: ILSI Press, International Anaemia Consultative Group (INCAG); 1998

2. Stoltzfus RJ, Mullany L, Black RE. Iron deficiency anaemia. In: Comparative Quantification of Health Risks: Global and Regional Burden of Disease Attributable to Selected Major Risk Factors. Vol. 1. Ch. 3. Geneva: World Health Organization; 2004.

3. de Benoist B, McLean E, Egli I, Cogswell M, editors. Worldwide Prevalence of Anaemia 1993-2005: WHO Global Database on Anaemia. Geneva: World Health Organization; 2008.

4. Rasmussen KM. Is there a causal relationship between iron deficiency or iron-deficiency anaemia and weight at birth, length of gestation and perinatal mortality? J Nutr 2001;131(2S-2):590S-601.

5. Scholl TO. Iron status during pregnancy: Setting the stage for mother and infant. Am J Clin Nutr 2005;81(5):1218S-22.

6. Titaley CR, Dibley MJ, Roberts CL, Hall J, Agho K. Iron and folic acid supplements and reduced early neonatal deaths in Indonesia. Bull World Health Organ 2010;88:500-8.

7. Statistics Indonesia, National Family Planning Coordinating Board, Ministry of Health, ORC Macro. Indonesia Demographic and Health Survey 2012. Calverton, Maryland: BPS and ORC Macro; 2013.

8. National Institute of Health Research and Development MOH, Republic of Indonesia. Basic Health Research 2013: National Report 2013. Jakarta: National Institute of Health Research and Development, Ministry of Health, Republic of Indonesia; 2013.

9. Filmer D, Pritchett LH. Estimating wealth effects without expenditure data--or tears: An application to educational enrollments in States of India. Demography 2001;38(1):115-32.

10. Bener A, Al Maadid MG, Al-Bast DA, Al-Marri S. Maternal knowledge, attitude and practice on folic acid intake among Arabian Qatari women. Reprod Toxicol 2006;21(1):21-5.

11. Ren A, Zhang L, Li Z, Hao L, Tian Y, Li Z. Awareness and use of folic acid, and blood folate concentrations among pregnant women in northern China - An area with a high prevalence of neural tube defects. Reprod Toxicol 2006;22(3):431-6.

12. Gebremedhin S, Samuel A, Mamo G, Moges T, Assefa T. Coverage, compliance and factors associated with utilization of iron supplementation during pregnancy in eight rural districts of Ethiopia: A cross-sectional study. BMC Public Health 2014;14:607.

13. Robbins JM, Cleves MA, Collins HB, Andrews N, Smith LN, Hobbs CA. Randomized trial of a physician-based intervention to increase the use of folic acid supplements among women. Am J Obstet Gynecol 2005;192(4):1126-32.

14. Girard AW, Olude O. Nutrition education and counselling provided during pregnancy: Effects on maternal, neonatal and child health outcomes. Paediatr Perinat Epidemiol 2012;26 Suppl 1:191-204.

15. Galloway R, Dusch E, Elder L, Achadi E, Grajeda R, Hurtado E, et al. Women's perceptions of iron deficiency and anemia prevention and control in eight developing countries. Soc Sci Med 2002;55(4):529-44.

16. Lutsey PL, Dawe D, Villate E, Valencia S, Lopez O. Iron supplementation compliance among pregnant women in Bicol, Philippines. Public Health Nutr 2008;11(1):76-82

17. Seck BC, Jackson RT. Determinants of compliance with iron supplementation among pregnant women in Senegal. Public Health Nutr 2008;11(6):596-605.

18. Joshi H, Joshi M, Ranjan P, Misra S, Verma P, Rana M, et al. Refresher training on maternal and child health for urban community health volunteers: Assessing knowledge and skills. Internet J Med Update 2006;1(2)18-24

19. Sistiarani C, Dardjito E, Nurhayati S. Educational leaflet to improve mothers knowledge about utilization. In: Maternal and Child Health 
Book. Vol. 1. Kalibagor, Indonesia. Management in Health; 2015. p. XIX.

20. Adawiyani R. Pengaruh pemberian booklet anaemia terhadap pengetahuan, kepatuhan minum tablet tambah darah dan kadar hemoglobin ibu hamil. J Ilmiah Mahasiswa Univ Surabaya 2013;2(12):50-4
21. Lunet N, Rodrigues T, Correia S, Barros H. Adequacy of prenatal care as a major determinant of folic acid, iron, and vitamin intake during pregnancy. Cad Saude Publica 2008;24(5):1151-7.

22. Kalimbira AA, Mtimuni BM, Chilima DM. Maternal knowledge and practices related to anaemia and iron supplementation in rural malawi: A crosssectional study. Afr J Food Agric Nutr Dev 2009;9(1):550. 